Gut, 1979, 20, 300-304

\title{
Influence of intestinal transit time on azo-reduction of salicylazosulphapyridine (Salazopyrin)
}

\author{
P. A. M. van HeES ${ }^{1}$, J. H. M. TUINTE, J. M. van ROSSUM, AND \\ J. H. M. VAN TONGEREN
}

From the Department of Medicine, Division of Gastroenterology, St Radboud Hospital, Nijmegen, and Department of Pharmacology, University of Nijmegen, The Netherlands

SUMMARY During a normal and an accelerated intestinal transit, in seven healthy volunteers, the recoveries of salicylazosulphapyridine (SASP) and its split products sulphapyridine (SP) and 5-aminosalicylic acid (5-ASA) were determined in urine and faeces. The azo-reduction of SASP and consequently the recovery of 5-ASA in the faeces was found to be substantially decreased during an accelerated intestinal transit. In addition, in 18 patients with inflammatory disease of the colon during maintenance therapy of SASP it could be demonstrated that the serum SP levels were related to the diarrhoeal state and did not correlate with disease activity. As recent studies have reported that 5-ASA is possibly the active therapeutic moiety of SASP, the ineffectiveness of SASP therapy in patients with active colitis may be ascribed to the reduced azo reduction of SASP as the result of profuse diarrhoea.

Salicylazosulphapyridine (Salazopyrin, Sulphasalazine, SASP) has been widely used in the treatment of ulcerative colitis and Crohn's disease. However, its mode of action is still unknown. SASP is composed of sulphapyridine (SP) in azo-linkage with 5-aminosalicylic acid (5-ASA). After an oral dose of SASP in man, only a small fraction has been found to be absorbed in the small bowel and excreted in the urine. The greater part of the drug reaches the colon and is almost completely split at the diazo bond by bacterial azo-reductases into SP and 5-ASA (Schröder and Campbell, 1972; Peppercorn and Goldman, 1973). SP is then mostly absorbed and subsequently partially metabolised in the liver (acetylation and glucuronidation) before excretion in the urine. The 5-ASA moiety is largely recovered in the faeces and only a small portion is found in the urine as acetylated form.

As SASP is particularly effective in the treatment of inflammatory disease of the large bowel, it has been suggested that one of the metabolites, rather than SASP itself, is responsible for the drug's activity at the site of breakdown. Although controlled trials have established the value of SASP in

\footnotetext{
${ }^{1}$ Address for correspondence: P. A. M. van Hees, Department of Medicine, Division of Gastroenterology, St 'Radboud Hospital, Geert Grooteplein Zuid 16, Nijmegen, The Netherlands.

Received for publication 2 October 1978
}

mild and moderate active colitis (Baron et al., 1962; Dick et al., 1964) and in maintenance therapy to prevent recurrence of the disease (Misiewicz et al., 1965; Dissanayake and Truelove, 1973) SASP even in a high dose is not very effective in patients with severe colitis. The relative ineffectiveness of the drug in such situations might be attributed to a reduction of the breakdown of SASP because of severe diarrhoea. Therefore, the influence of the intestinal transit time and the disease activity on the azoreduction of SASP was studied.

\section{Methods}

\section{PATIENTS}

Seven healthy male volunteers with no previous history of gastrointestinal disorders or diarrhoea were studied with their informed consent. No drugs had been consumed in the three months before the investigations. The recoveries of SASP, SP (total amount of SP, acetyl-SP, SP-glucuronide, and acetyl-SP-glucuronide) and 5-ASA (total amount of 5-ASA and acetyl-5-ASA) in urine and faeces were determined during a normal and an accelerated intestinal transit.

After a 12 hour period of fasting, at 9 am of day 1 , the subjects were given orally a single $3 \mathrm{~g}$ dose of SASP in powder form, together with a standardised breakfast and $5 \mu \mathrm{Ci}{ }^{51} \mathrm{CrCl}_{3}$. At $1 \mathrm{pm}$ a standardised lunch was given. Except water and tea no other 
foodstuffs were consumed until $6 \mathrm{pm}$ on the first day. Twenty-four hour urine specimens were collected for four days. In this period, the time and frequency of defaecation was noted $(0-2$ solid stools per day). The stool of every passage was collected separately in a box and mixed with a solution of $0.2 \% \mathrm{HgCl}_{2}$. Addition of an enzyme inhibitor such as $\mathrm{HgCl}_{2}$ to the faeces is necessary to prevent further azo-reduction of SASP during storage. An accelerated intestinal transit time was then induced by using bisacodyl (Dulcolax, 3-6 tablets per day). This laxative was chosen because the effect is exerted mainly on the colon (Fingl, 1975). By this treatment, all subjects had four or more watery stools per day. The experiment was then repeated in this period, usually one week after the first part of the experiment.

The intestinal transit time was determined by measuring the radioactivity of ${ }^{51} \mathrm{Cr}$ in each sample of faeces. Intestinal transit time was defined as the period between the time of ${ }^{51} \mathrm{CrCl}_{3}$ ingestion and the moment when at least $90 \%$ of ${ }^{51} \mathrm{Cr}$ was excreted in the stools. All the samples were then pooled and homogenised.

To investigate whether the inflammatory activity of the large bowel may influence the metabolism of SASP, serum levels of SASP and SP (SP+ac-SP) were determined in 18 patients with inflammatory disease of the colon who were taking a maintenance dose of $6 \mathrm{~g}$ SASP per day, during both active and quiescent phases of the disease. The assessment of disease activity was based on clinical, radiological, and endoscopic criteria. In nine patients the stool frequency and consistency remained unchanged in both periods $(2.6 \pm 1.2$ (mean \pm SD) soft or solid stools per day). Nine other patients had more severe diarrhoea (4.8 \pm 2.4 watery or soft stools per day) in the active phase of the disease and almost normal defaecation $(2.0 \pm 0.9$ soft or solid stools per day) during a remission.

To investigate the possible effects of bisacodyl on azo-reduction of SASP the following in vitro study was carried out. Immediately after defaecation, the faeces of a healthy subject were homogenised and diluted 10 times, partly with a $0.9 \% \mathrm{NaCl}$ solution and partly with a bisacodyl solution $(5 \mathrm{mg}=1$ tablet in $50 \mathrm{ml} 0.9 \% \mathrm{NaCl}$ ). $\mathrm{pH}$ was adjusted to 7.5 by adding $0.02 \mathrm{~mol}$ veronal buffer. Then SASP was added to a concentration of $100 \mu \mathrm{g} / \mathrm{ml}$ faecal suspension. One millilitre aliquots of these faecal suspensions were incubated at $37^{\circ} \mathrm{C}$. One millilitre $0.2 \% \mathrm{HgCl}_{2}$ solution was added to $1 \mathrm{ml}$ suspension (to stop the azo-reduction of SASP) at $0,10,30,60$, 120,180 , and 240 minutes after incubation. In each sample of faeces the concentration of SP was determined. In this way the reduction rate of the azo bond of SASP could be determined both in a faeces suspension without and with bisacodyl.

To study whether the faecal flora of patients with severe colitis was capable of reducing SASP at similar rates, the faecal concentrations of SASP and SP were determined at different times after defaecation in a patient with active colitis and severe diarrhoea (six to eight watery stools per day) using a maintenance dose of $6 \mathrm{~g}$ SASP per day. Immediately after defaecation the faeces were homogenised and diluted (three times) as described above. One millilitre aliquots of the faecal suspension were made. One millilitre $0.2 \% \mathrm{HgCl}_{2}$ solution was added to a $1 \mathrm{ml}$ sample immediately after defaecation and after incubation at $37^{\circ} \mathrm{C}$ for $0.5,1,2,3,4$, and 21 hours. In each sample of faeces the concentrations of SASP and SP were determined.

All specimens of serum, urine, and faeces were stored at $-20^{\circ} \mathrm{C}$ before analysis.

SASP and SP (free SP and acetylated and/or glucuronidated metabolites) were determined by the methods of Sandberg and Hansson (1973) and Hansson and Sandberg (1973). Analysis of 5-ASA (and ac-5-ASA) was carried out by a modified method of Pieniaszek and Bates (1975). SP and metabolites were extracted before determination of 5-ASA to avoid interference of ac-SP with the colour reaction of 5-ASA. All specimens of each subject were analysed in duplicate. The analytic errors for these methods were found to be less than $5 \%$, except for 5 -ASA in faeces (less than $10 \%$ ).

\section{Results}

In the healthy volunteers, the total recoveries in urine and faeces of SP and 5-ASA, including those remaining in the non-dissociated parent compound (SASP), were $82.4 \pm 11.9 \%$ (mean \pm SD) and $97.7 \pm 15.4 \%$ of the ingested dose, respectively. The recoveries of SASP, SP, and 5-ASA in urine and faeces after a single oral dose of $3 \mathrm{~g}$ SASP in normal and in accelerated intestinal transit are summarised in the Table. Where intestinal transit time was normal (35 to 93 hours) SASP was almost completely split in the colon. Only $3.2 \%$ of the given dose was found as SASP in urine and $0.5 \%$ in the faeces. SP was mainly recovered in the urine $(63.1 \%$ of the total amount of SP in SASP), whereas 5-ASA was largely excreted in the faeces $(74.4 \%)$. These findings agree with those found by Peppercorn and Goldman (1973). Where intestinal transit time was accelerated (eight to 28 hours), $45.4 \%$ of the administered SASP was found unchanged in the faeces. The recovery of 5-ASA in the faeces decreased to $45.5 \%$. The recovery of SASP in urine was not influenced by the intestinal transit time. Although 
Table Influence of intestinal transit time on recoveries of SASP, SP, and 5-ASA in urine and faeces of seven healthy volunteers, after single oral dose of $3 \mathrm{~g} S A S P$

\begin{tabular}{|c|c|c|c|c|c|c|c|c|}
\hline & \multicolumn{8}{|c|}{ Recovery $($ mean $\pm S D)$} \\
\hline & \multicolumn{4}{|c|}{ Normal intestinal transit $(35-93 h)$} & \multicolumn{4}{|c|}{ Accelerated intestinal transit $(8-28 h)$} \\
\hline & \multicolumn{2}{|l|}{ Urine } & \multicolumn{2}{|l|}{ Faeces } & \multicolumn{2}{|l|}{ Urine } & \multicolumn{2}{|l|}{ Faeces } \\
\hline & (mg) & $(\% \ddagger)$ & $(m g)$ & $(\%)$ & $(m g)$ & (\%†) & (mg) & $(\% \ddagger)$ \\
\hline $\begin{array}{l}\text { SASP } \\
\text { SP* } \\
\text { 5-ASA } \dagger\end{array}$ & $\begin{array}{r}96 \\
1184 \quad 66 \\
210 \pm 86\end{array}$ & $\begin{array}{l}(3.2 \pm 2 \cdot 2) \\
(63 \cdot 1 \pm 7 \cdot 6) \\
(18.5 \pm 7.6)\end{array}$ & $\begin{array}{r}15 \pm 18 \\
137 \pm \\
846 \pm 152\end{array}$ & $\begin{array}{l}(0.5 \pm 0.6) \\
(7.3 \pm 2.7) \\
(74.7 \pm 13.4)\end{array}$ & $\begin{array}{r}81 \pm 48 \\
437 \pm 272 \\
67 \pm 46\end{array}$ & $\begin{array}{l}(2.7 \pm 1.6) \\
(23.3 \pm 14.5) \\
(5.9 \pm 4.1)\end{array}$ & $\begin{array}{r}1362 \pm 639 \\
364 \pm 158 \\
515 \pm 292\end{array}$ & $\begin{array}{l}(45.4 \pm 21.3) \\
(19.4 \pm 8.4) \\
(45.5 \pm 25.8)\end{array}$ \\
\hline
\end{tabular}

*SP plus acetylated and glucuronidised metabolites.

†-ASA plus acetyl 5-ASA.

$\ddagger$ Percentage of the ingested dose; for SP and 5-ASA based on the molar recoveries of SP and 5-ASA respectively, in comparison with SASP ingested. Three grams SASP contain $1877 \mathrm{mg}$ SP and $1133 \mathrm{mg}$ 5-ASA.

there was diminished splitting of SASP in the intestine, the faecal SP was found to be increased $(7.3 \%$ in normal transit versus $19.4 \%$ in accelerated transit). These findings indicate that the absorption of SP in the colon is reduced as a result of accelerated transit time.

Figures 1, 2, and 3 show the recoveries of SASP, SP, and 5-ASA, respectively, in the individual subjects. The azo-reduction of SASP and consequently the recovery of 5-ASA in the faeces was substantially decreased, particularly in subjects with an intestinal transit time of less than 16 hours.

In 18 patients with colitis ingesting a maintenance dose of $6 \mathrm{~g}$ SASP per day, the serum SASP level was unchanged during active and quiescent phase of the disease, irrespective of the changes in frequency of

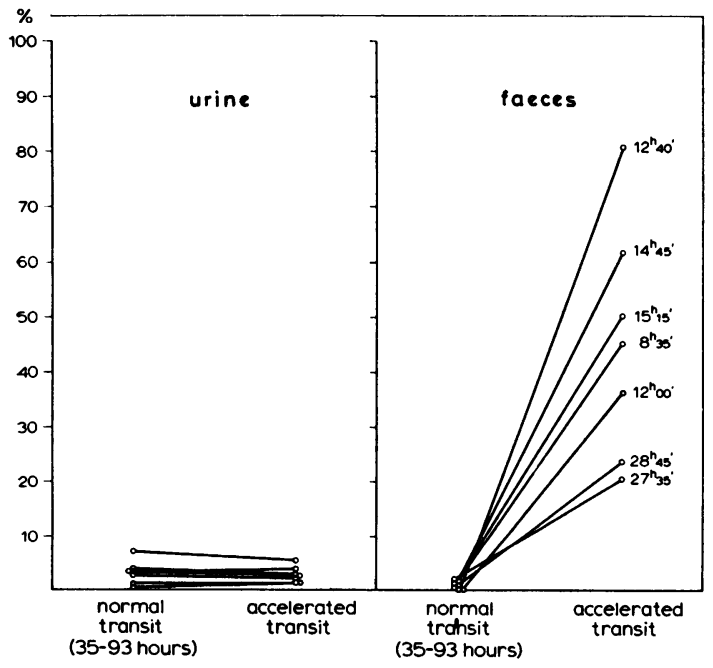

Fig. 1 Urinary and faecal recoveries of salicylazosulphapyridine (SASP) in healthy volunteers after ingestion of a single dose of $3 \mathrm{~g} S A S P$ during a normal and an accelerated intestinal transit.

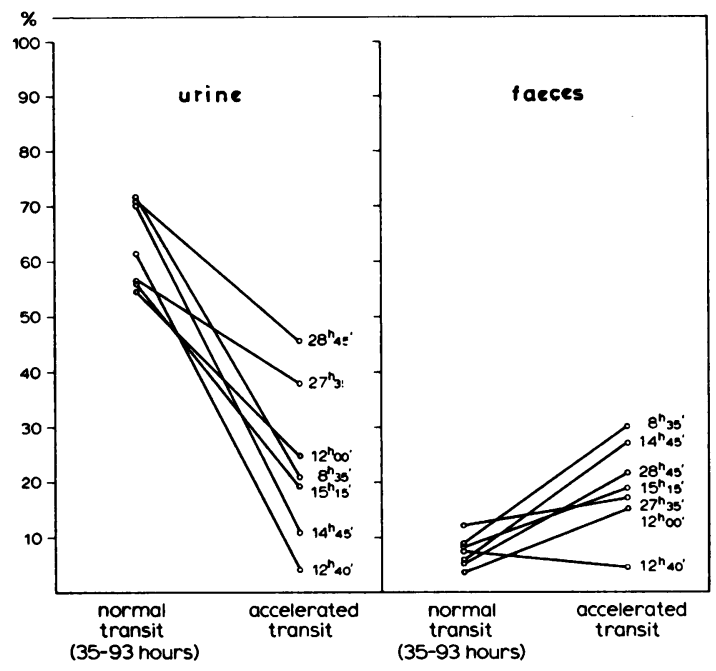

Fig. 2 Urinary and faecal recoveries of sulphapyridine in healthy volunteers after ingestion of a single dose of $3 \mathrm{~g}$ SASP during a normal and an accelerated intestinal transit.

defaecation. In nine patients with unchanged stool characteristics the serum SP concentration in the active phase was the same as the concentration in the quiescent phase of the disease. However, in nine other patients whose diarrhoeal state improved during a remission, the serum SP levels substantially increased (Fig. 4).

Bisacodyl did not influence the azo reduction of SASP. The reduction rate of SASP in a faecal suspension both without and with bisacodyl was $0.4 \mathrm{mg}$ / $\mathrm{ml} / \mathrm{h}$.

In the patient with active colitis, the concentrations of SASP and SP in the faecal suspension immediately after defaecation were $1.2 \mathrm{mg} / \mathrm{ml}$ and $1.3 \mathrm{mg} / \mathrm{ml}$ respectively. The reduction rate of SASP was the same as in a faecal suspension of a healthy 


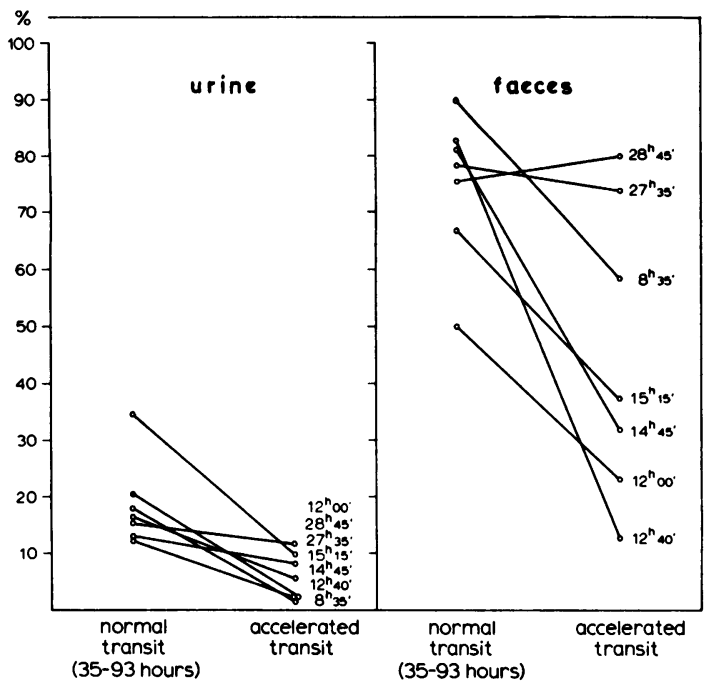

Fig. 3 Urinary and faecal recoveries of 5-aminosalicylic acid in healthy volunteers after ingestion of a single dose of $3 \mathrm{~g} S A S P$ during a normal and an accelerated intestinal transit.

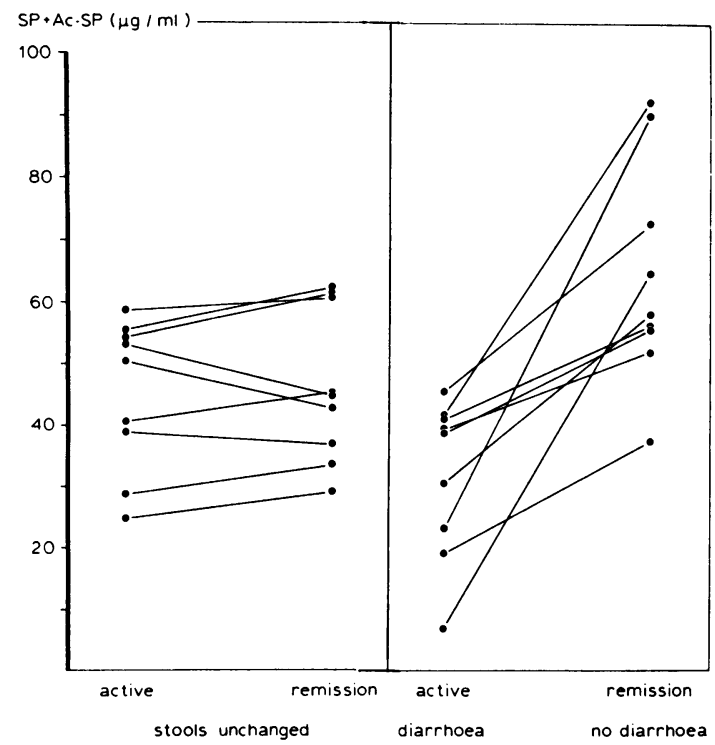

Fig. 4 Relation between serum sulphapyridine level, disease activity, and stool frequency in patients with inflammatory disease of the colon taking a daily dose of $6 \mathrm{~g} S A S P$.

subject: about $0.4 \mathrm{mg} / \mathrm{ml} / \mathrm{h}$. These results suggest that, at least in vitro, the faecal flora in healthy subjects and patients with severe colitis, have the same capacity to reduce SASP.

\section{Discussion}

From the studies of Baron et al. (1962) and Dick et al. (1964), it has been shown that SASP therapy is effective in mild and moderate active colitis. As it has been suggested that the active compound of SASP in the treatment of inflammatory bowel disease is 5-ASA (Khan et al., 1977; van Hees et al., 1978), it is possible that the ineffectiveness of SASP in severe colitis (colitis with severe diarrhoea) is due to an accelerated intestinal transit, so that the opportunity for colonic bacteria to carry out the azoreduction of SASP is diminished. In this study, we have demonstrated that an accelerated intestinal transit did indeed reduce the splitting of SASP in the large bowel. These results suggest that the intestinal transit time may play a key part in determining the drug's therapeutic effect. It seems important, therefore, to study whether antidiarrhoeal drugs might influence the efficacy of SASP in the treatment of patients with severe colitis.

In patients using SASP as maintenance therapy, Das et al. (1973) found that patients in remission had higher SP-levels than patients with an active colitis. They concluded that a serum SP-concentration within the range of $20-50 \mu \mathrm{g} / \mathrm{ml}$ could be considered to be the most effective therapeutic concentration. These results can be explained in two ways: (1) higher serum concentrations of SP cause healing in patients with active colitis, or (2) the diarrhoeal state in patients with active colitis prevents the attainment of a high serum SP-level.

From our present findings, it is clear that the serum SP-level depends on the intestinal transit time and is not correlated with the disease activity as such.

We wish to thank Willemijn van Beek, Mieke van Rens, and Ineke Verschuren for the determination of SASP and metabolites and the volunteers for their help. Dr S. H. Yap's helpful advice and criticism is gratefully acknowledged.

\section{References}

Baron, J. H., Connell, A. M., Lennard-Jones, J. E., and Avery Jones, F. (1962). Sulphasalazine and salicylazosulphadimidine in ulcerative colitis. Lancet, 1, 1094-1096.

Das, K. M., Eastwood, M. A., McManus, J. P. A., and Sircus, W. (1973). The metabolism of salicylazosulphapyridine in ulcerative colitis. I. The relationship between metabolites and the response to treatment in inpatients. II. The relationship between metabolites and the progress of the disease studied in outpatients. Gut, 14, 631-641.

Dick, A. P., Grayson, M. J., Carpenter, R. G., and Petrie, A. (1964). Controlled trial of sulphasalazine in the treatment of ulcerative colitis. Gut, 5, 437-442.

Dissanayake, A. S., and Truelove, S. C. (1973). A controlled therapeutic trial of long-term maintenance treatment of ulcerative colitis with sulphasalazine (Salazopyrin). Gut, 14, 923-926. 
Fingl, E. (1975). Laxatives and cathartics. In The Pharmacological Basis of Therapeuics, pp. 976-986. Edited by L. S. Goodman and A. Gilman. Macmillan: New York.

Hansson, K-A., and Sandberg, M. (1973). Determination of sulfapyridine and its metabolites in biological materials after administration of salicylazosulphapyridine. Acta Pharmacologica Suecica, 10, 87-92.

Hees, P. A. M. van, Tongeren, J. H. M. van, Bakker, J. H., and van Lier, H. J. J. (1978). Active therapeutic moiety of sulphasalazine (Letter). Lancet, 1, 277.

Khan, A. K. A., Piris, J., and Truelove, S. C. (1977). An experiment to determine the active therapeutic moiety of sulphasalazine. Lancet, 2, 892-895.

Misiewicz, J. J., Lennard-Jones, J. E., Connell, A. M., Baron, J. H., and Avery Jones, F. (1965). Controlled trial of sulphasalazine in maintenance therapy for ulcerative colitis. Lancet, 1, 185-189.

Peppercorn, M. A., and Goldman, P. (1973). Distribution studies of salicylazosulfapyridine and its metabolites. Gastroenterology, 64, 240-245.

Pieniaszek, H. J., Jr., and Bates, T. R. (1975). Colorimetric determination of 5-aminosalicylic acid and its $\mathrm{N}$-acetylated metabolite on urine and feces. Research Communications in Chemical Pathology and Pharmacology, 12, 571-581.

Sandberg, M., and Hansson, K-A. (1973). Determination of salicylazosulphapyridine in biological materials. Acta Pharmacologica Suecica, 10, 107-110.

Schröder, H., and Campbell, D. E. S. (1972). Absorption, metabolism, and excretion of salicylazosulfapyridine in man. Clinical Pharmacology and Therapeutics, 13, 539-551.

\section{The March 1979 Issue}

\section{THE MARCH 1979 ISSUE CONTAINS THE FOLLOWING PAPERS}

Radiographic and haemodynamic patterns of portal hypertension in hepatosplenic schistosomiasis: selection of surgical procedures M. A. EL-GENDI

Liver damage associated with perhexiline maleate D. LEWIS, H. C. WAINWRIGHT, M. C. KEW, S. ZWI, AND C. ISAACSON

Changes in hepatitis B virus DNA polymerase in relation to the outcome of acute hepatitis type $B$ A. Alberti, S. DIANA, A. L. W. F. EDDLESTON, AND ROGER WILLIAMS

Non-invasive techniques in the diagnosis of jaundice -ultrasound and computer P. G. WHEELER, A. THEODOSSI, R. PICKFORD, J. LAWS, R. P. KNILL-JONES, AND ROGER WILLIAMS

Plasma glucagon in diabetes of haemochromatosis: too low or too high? W. A. MULLER, M. BERGER, H. J. CÜPPERS, P. BERCHTOLD, G. STROHMEYER, A. E. RENOLD, J. R. HOFSTETTER, AND J.-J. GONVERS

Relationship between endotoxaemia and protein concentration of ascites in cirrhotic patients $\mathrm{K}$. TARAO, T. MOROI, Y. NAGAKURA, T. IKEUCHI, T. SUYAMA, O. ENDO, AND K. FUKUSHIMA

Patchy enteropathy in childhood P. D. MANUEL, J. A. WALKER-SMITH, AND N. E. FRANCE

Amylase activity in human bile L. A. DONALDSON, S. N. JOFFE, W. MCINTOSH, AND M. J. BRODIE
Demonstration of human apolipoprotein $\mathrm{A}$ in isolated mucosal cells from small intestine and isolated hepatocytes U. HOPF, G. ASSMANN, H.-E. SCHAEFER, AND A. CAPURSO

HLA AW19, B12 in immunoproliferative small intestinal disease B. NIKBIN, M. BANISADRE, F. ALA, AND A. MOJTABAI

Oral BCG vaccine in Crohn's disease w. $R$. BURNHAM, J. E. LENNARD-JONES, P. HECKETSWEILER, R. COLIN, AND Y. GEFFROY

Effects of age, antigen deprivation, and allograft rejection on epithelial cell kinetics in mouse colon R. J. HOLDEN AND ANNE FERGUSON

Colonic adenomas-a colonoscopy survey P. E. GILLESPIE, T. J. CHAMBERS, K. W. CHAN, F. DORONZO, B. C. MORSON, AND C. B. WILLIAMS

Cell proliferation in the human gallbladder epithelium: effect of distension Ph. PUTZ AND G. WILLEMS

Postprandial gastric function in pancreatic insufficiency P. T. REGAN, JUAN-R. MALAGeladA, E. P. DIMAGNO, AND V. L. W. GO

\section{Case report}

Hepatocellular carcinoma in primary biliary cirrhosis: report of four cases N. KRASNER, P. J. JOHNSON, B. PORTMANN, G. WATKINSON, R. N. M. MACSWEEN, AND ROGER WILLIAMS

Notes and activities; Books

Copies are still available and may be obtained from the PUBLISHING MANAGER, BRITISH MEDICAL ASSOCIATION, TAVISTOCK SQUARE, LONDON, WC1H 9JR, price $£ 3 \cdot 50$, including postage 